\author{
Johannes Weigel
}

\title{
Organvermittlung und Arzthaftung
}

Regelungskonzept, Verfassungsmäßigkeit, Rechtsnatur und arzthaftungsrechtliche Konsequenzen des Systems der Organvermittlung

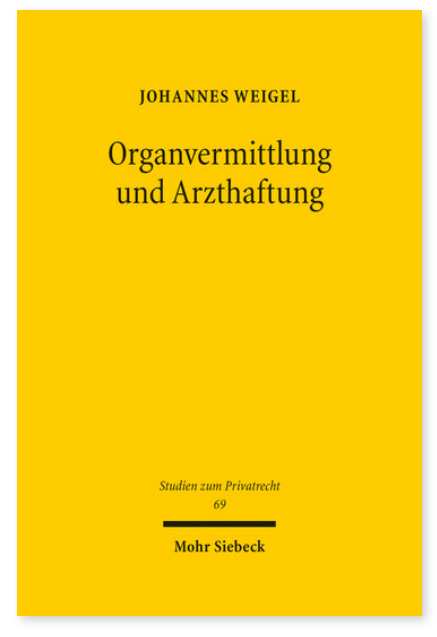

2017. XXIII, 337 Seiten. StudPriv 69

ISBN 978-3-16-155455-1

DOI 10.1628/978-3-16-155455-1

eBook PDF 114,00€

ISBN 978-3-16-155454-4

Leinen $114,00 €$
Der in Deutschland chronisch vorherrschende Mangel an Spenderorganen zwingt den Gesetzgeber zu einem Verteilungssystem, das über Leben und Tod der wartenden Patienten entscheidet. Das derzeitige wird von Richtlinien der Bundesärztekammer mit seinen Wartelisten- und Verteilungsverfahren geprägt und sieht sich dabei starker verfassungsrechtlicher Kritik ausgesetzt. Dabei wird es in zunehmendem Maße rechtspolitisch in Frage gestellt. Zu dieser schwierigen Lage des deutschen Transplantationsrechts gesellt sich in letzter Zeit ein erheblicher Verlust des Systemvertrauens der Bevölkerung durch manipulative Eingriffe behandelnder Ärzte und fehlerhafte Organvermittlungen. Die Frage, wie sich verfassungsrechtliche Unsicherheiten der BÄK-Richtlinien auf die zivilrechtliche Arzthaftung auswirken, unter welchen Voraussetzungen ein behandlungsvertrags- und deliktsrechtlicher Schuldvorwurf erhoben werden kann und wie sich die Rechtssätze der BÄK zivilrechtsdogmatisch in die Arzthaftung einordnen lassen, ist Kernthema der vorliegenden Untersuchung.

Die Arbeit wurde mit dem Fakultätspreis Wintersemester 2016/17 der Juristischen Fakultät der LMU München, dem Promotionspreis der Münchener Juristischen Gesellschaft 2017 sowie dem Wissenschaftspreis der Gesellschaft für Recht und Politik im Gesundheitswesen ausgezeichnet.

Johannes Weigel Geboren 1992; Studium der Rechtswissenschaften an der Ludwig-Maximilians-Universität München sowie Betriebswirtschaftslehre an der Humboldt-Universität zu Berlin; 2015 Erste Juristische Prüfung; Wissenschaftlicher Mitarbeiter am Lehrstuhl für Bürgerliches Recht und Medizinrecht der LMU; 2016 Promotion; seit 2017 Rechtsreferendar am Kammergericht Berlin.
Jetzt bestellen:

https://mohrsiebeck.com/buch/organvermittlung-und-arzthaftung-9783161554551?no_cache=1

order@mohrsiebeck.com

Telefon: $+49(0) 7071-923-17$

Telefax: $+49(0) 7071-51104$ 